\title{
Evaluation of Subsurface Damage in Concrete Deck Joints Using Impact Echo Method
}

\author{
Larry Rickard ${ }^{1}$ and Wonchang Choi $^{2}$ \\ ${ }^{1}$ Sandia National Laboratories, Kansas City, MO 64147, USA \\ ${ }^{2}$ Department of Architectural Engineering, Gachon University, Seongnam, Gyeonggi-do 461-701, Republic of Korea \\ Correspondence should be addressed to Wonchang Choi; wonchang.choi@gmail.com
}

Received 14 January 2016; Accepted 5 May 2016

Academic Editor: Kaveh Edalati

Copyright ( 2016 L. Rickard and W. Choi. This is an open access article distributed under the Creative Commons Attribution License, which permits unrestricted use, distribution, and reproduction in any medium, provided the original work is properly cited.

Many factors can affect the overall performance and longevity of highway bridges, including the integrity of their deck joints. This study focuses on the evaluation of subsurface damage in deteriorated concrete deck joints, which includes the delamination and corrosion of the reinforcement. Impact echo and surface wave technology, mainly a portable seismic property analyzer (PSPA), were employed to evaluate the structural deficiency of concrete joints. Laboratory tests of core samples were conducted to verify the nondestructive test results. The primary advantage of the PSPA as a bridge assessment tool lies in its ability to assess the concrete's modulus and to detect subsurface defects at a particular point simultaneously.

\section{Introduction}

The American Society of Civil Engineers (ASCE) reported in 2009 that 30 percent of North Carolina's bridges were structurally deficient or functionally obsolete [1]. As of January 2010 North Carolina had 13,251 bridges in its inventory. Of these, 2,739, or 20.6 percent, were deemed functionally obsolete, and 2,557, or 19.29 percent, were considered structurally deficient [2].

Many factors can affect the overall performance and longevity of highway bridges, which includes the integrity of their deck joints. The type of joint to be installed usually is decided upon during the design stage. Two primary factors are considered: the length of the expansion to be accommodated (measured normal to the centerline) and the bridge's skew angle [3].

Three types of armored joints are commonly used in bridges. The first is a type of closed joint that employs an extruded neoprene gland. These types of joints typically are used for movements of 2.5 inches $(65 \mathrm{~mm})$ or less and consist of two parallel steel anchors fitted on opposite sides of the joint and placed below the finished grade. The second type of joint is the armored "Evazote" seal, which uses anchors similar to those used in the gland type, except that the holddown bars (and associated hardware) are omitted and the anchors are placed at or just slightly below the deck's finished grade. The waterproofing member in this case is a closedcell compression seal made of polyethylene copolymer foam. These joints also typically are used in members that exhibit movement of $65 \mathrm{~mm}$ or less [4]. The third type is the finger joint (see Figure 1). It is usually considered a type of open joint and historically has been used to accommodate moderate to large structural movements of approximately $76 \mathrm{~mm}$ or greater. Finger joints can still be found on some larger bridges built during the mid-twentieth century. These joints were relatively inexpensive to install and tend to be very durable, experiencing few problems during their operational lifetime [3].

An earlier study of joint types was performed by the Pennsylvania Department of Transportation (PennDOT) during the mid-1980s. This Federal Highway Administrationsponsored project was in response to an earlier study that found that 76 percent of the joints in use were either leaking or completely unsealed. The PennDOT study investigated a wide range of joint types that included armored neoprene and preformed neoprene seals. Engineers discovered a high rate 


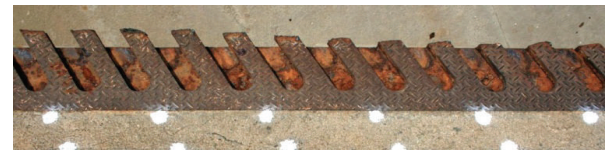

FIgURE 1: Finger joints used in this study.

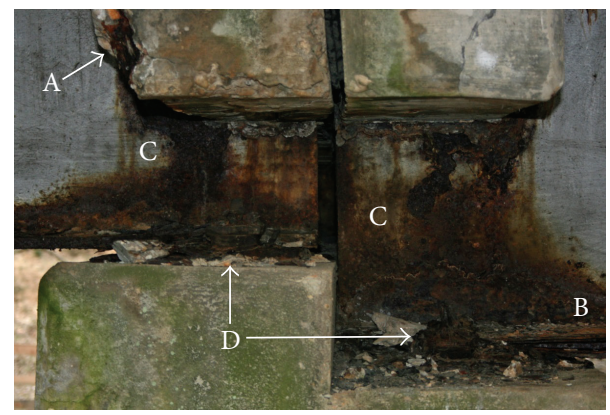

FIGURE 2: Example of a structurally deficient deck joint.

of failure in the anchorage systems of these joints, especially those that were skewed. It was recommended that future joint anchorages should be cast integrally with the surrounding concrete and tied to the reinforcing steel [6].

The determination of the status of a structurally deficient deck joint was based primarily on evidence of extensive deterioration in several of the major structural members, a substantial amount of which was caused by apparent chloride intrusion due to seepage through the original joints. Some of this seepage undoubtedly occurred during the early life of the structure when its original bare concrete wearing surface was still exposed. As that surface deteriorated, at least one layer of asphalt concrete was applied. When fresh, this additional cover helped seal the original deck joints, but decades of movement, freeze-thaw cycles, and so forth caused cracks to appear, thus allowing further seepage.

Figure 2 shows a case of a structurally deficient deck joint. Apparent chloride intrusion has caused corrosion of the rebar, resulting in spalling of the exterior concrete (A). Years of direct exposure to water and deicing agents have caused extensive corrosion of the girder ends, with a resulting loss of the section at both ends. This loss is much more severe on the lower flanges of each girder, where water tended to accumulate. Delamination of the steel in the lower flange is evident at (B), which would likely exacerbate any reduction in shear capacity caused by the section loss in the web, shown at (C). Corrosion of the bearing bolts (D) is so severe that only vestiges of them remain. Little or no sound steel is left to fix the girders in place.

This research investigates an extension of the use of impact echo (IE) methods using a portable seismic property analyzer (PSPA) to detect subsurface defects and anomalies in and around bridge deck armor. The nondestructive methods used in this study are feasible to evaluate the structural integrity of concrete structures in the field [7-9].

Particular attention is paid to exploring the challenges that are unique to these techniques with regard to armored deck joints and to their potential use as an alternative or adjunct to conventional nondestructive testing techniques. In addition, this work will attempt to quantify the results and investigate the possible feasibility of their incorporation into existing bridge maintenance programs.

\section{Experimental Program}

The accurate marking of the test area was necessary for the proper use of the PSPA and to ensure the reliability and repeatability of the results. Figure 3 illustrates the deck marking procedure. The centerline of the bridge was marked first, because the deck's crown could interfere with the chalk line. A fiberglass engineer's tape measure was stretched across the deck at the joint interface, the distance noted, and a "crow's foot" mark drawn at the halfway point with a felt-tip marker. Next, the station points plus one point $0.91 \mathrm{~m}$ from the interface were drawn at each gutterline. The tape was stretched across the $0.91 \mathrm{~m}$ points, and a second centerline point was marked as before. A steel engineer's tape measure and felt-tip marker were then used to mark the station points at the centerline. Finally, the chalk line was stretched and snapped between corresponding pairs of station points. This process began by stretching the fiberglass tape parallel to the chalk line for Station 1. The tape was shifted until an even foot on the tape corresponded to the centerline. A lumber crayon was then used to mark each offset from the centerline in $0.30 \mathrm{~m}$ intervals. This process was repeated for each station until the offsets for all stations were marked. In addition, ground penetration radar (GPR) in the related research has been conducted. Detailed procedures can be found elsewhere $[5,10]$.

An initial review of the IE data verified the deck's poor overall condition. The IE signature for most of the test points displayed numerous high-amplitude echoes at different depths, which is evidence of significant deterioration. This phenomenon was observed with reasonable consistency throughout the test area. An attempt was made to quantify and map these data, but no reasonable means to do so could be formulated. Therefore, the IE signature for each test point was reviewed individually and compared to the frequency and modulus plots.

Another observed phenomenon was the apparent $50 \mathrm{~mm}$ offset in the thickness of the concrete. This offset had to be subtracted from any reading on the scale in order to determine the correct depth of a given defect. The bottom "knee" of the IE graph indicates a depth of $200 \mathrm{~mm}$; subtracting $50 \mathrm{~mm}$ from this reading yields a total depth of $150 \mathrm{~mm}$ in this location. This finding was subsequently verified during the collection of core samples.

\section{Results and Discussion}

3.1. Processing IE Data. The PSPA is controlled and its data processed by a program called PSPA Manager. This software runs in the attached computer and performs the necessary discrete Fourier transform (DFT) on each waveform and interprets the results. The PSPA test output for a given measurement is presented visually using two different tabbed 


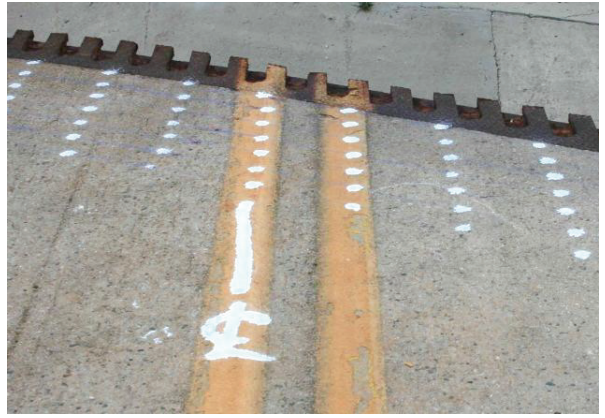

(a)

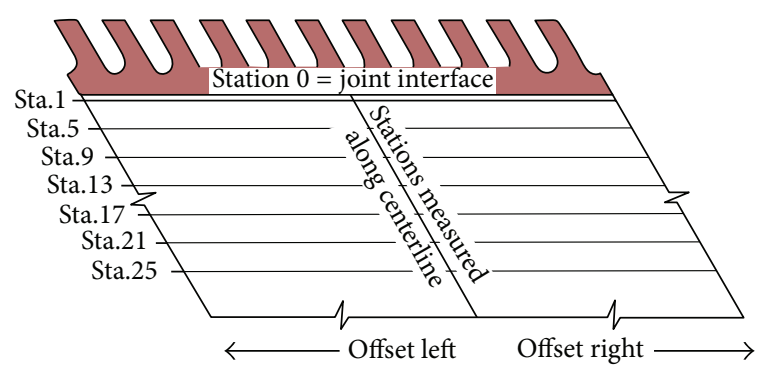

(b)

FIGURE 3: Reference points and mapping sequences.

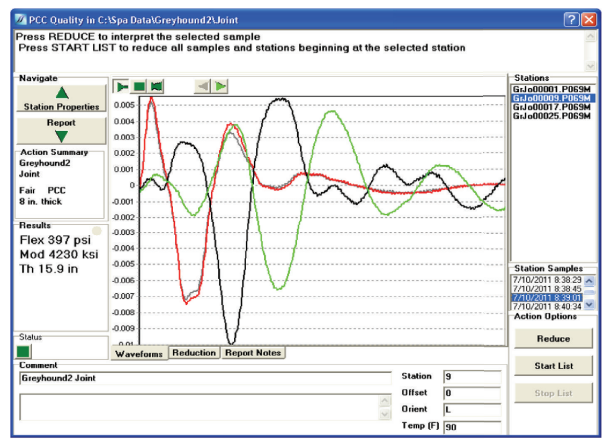

(a) Standard amplitude versus time plot

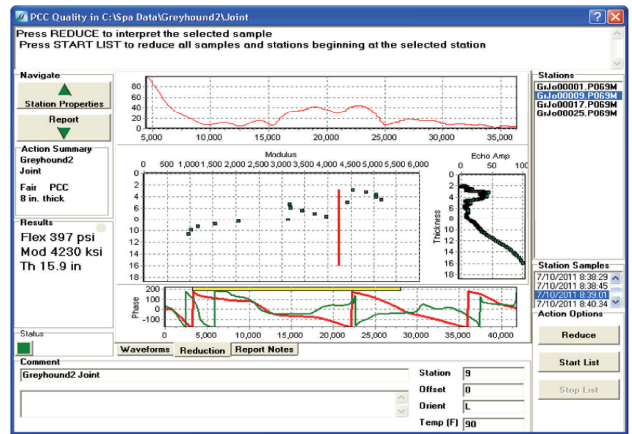

(b) Interpretation of waveform values

FIGURE 4: Data processing windows in PSPA Manager.

windows. Both windows display data regarding the location of the test point and its flexural strength, dynamic modulus, and thickness. Data from the PSPA test also can be output as waveform files and in report form.

Figure 4(a) shows an interpretation of the waveform values and Figure 4(b) shows the values divided into four separate graphs. Figure 4(a) presents a standard amplitude versus time plot of three separate signals. The original pulse initiated by the source is shown as a red line on the plot. The signals detected by the near and far receivers are shown as black and green lines, respectively. One item of interest is the relatively rapid attenuation of the source signal over time when compared to the two receiver signals. Also noteworthy is the time shift between the near and far receiver peaks.

The top graph in Figure 4(b) displays amplitude versus frequency, which is essentially the DFT of the signals shown in the waveforms display. This example shows that the dominant frequency of the test point lies somewhere around $23 \mathrm{kHz}$, with a minor peak around $18.5 \mathrm{kHz}$.

The second graph, located toward the center of the window in Figure 4(b), illustrates the relationship between depth and dynamic modulus. The graph is produced by measuring the R-wave velocity through the material using data received from both receivers. The green squares signify the discrete modulus values at various depths within the slab. The vertical red line represents the slab's average modulus value. In general, the closer horizontal spacing of these points is indicative of more sound material. The individual points shown in the example suggest that the strength of the concrete at the test point decreases with depth.

Toward the middle right of the display window in Figure $4(\mathrm{~b})$ is the IE graph. The data represented here are a product of the P-waves measured between the source and the near receiver. The echo amplitude is measured on the graph's horizontal axis, and depth is registered on the vertical axis. Significant echo amplitudes indicate areas of possible delamination or another deterioration at the indicated depth.

The final graph is the phase diagram, located at the bottom of Figure 4(b). This graph is a plot of the phase of the received signal as a function of frequency. Raw data are represented by the green line, and the best-fit line is shown in red. The example indicates a poor correlation between the two lines; ideally, these should lie roughly atop one another. The horizontal yellow bar denotes those frequencies used to calculate wave velocity.

3.2. Data Analysis Obtained from PSPA Test Results. The deterioration maps based upon the PSPA test results with dynamic elastic modulus values are shown in Figure 5. According to this set of data, most of the moderate to severe delamination appears to lie in the area to the left of the centerline. The entire area approximately $2.1 \mathrm{~m}$ to the right of the gutter appears to be in relatively poor condition, with no reading over $13.8 \mathrm{GPa}$. The most severe deterioration is at 


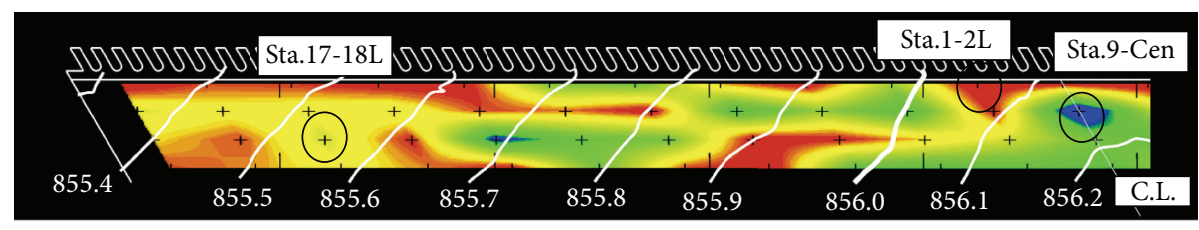

Offsets left

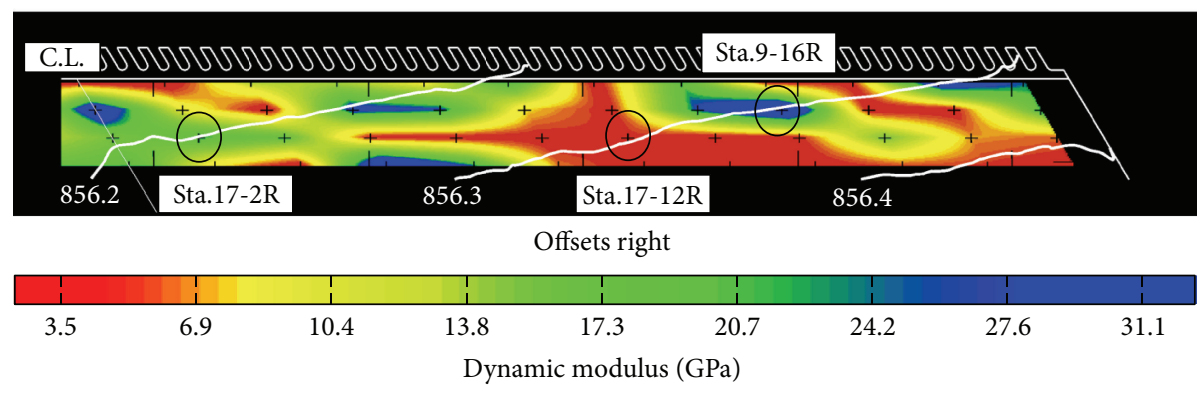

FIGURE 5: Contour maps of PSPA results and locations of core samples taken in this study.

the joint interface and in several intermittent areas toward the centerline. The other readings show modulus values in the range of $13.8 \mathrm{GPa}$ to $20.7 \mathrm{GPa}$, with no reading over $23.7 \mathrm{GPa}$.

Similar results were obtained using the data for the right half side of the joint. Although a few readings indicate the presence of sound concrete (modulus $>23.7 \mathrm{GPa}$ ), the overall quality of the concrete is very poor. Areas of severe, moderate, and slight deterioration can be detected in the immediate vicinity of the joint interface. An extensive area of severe deterioration can be expected beginning at the approximate center of the lane and extending toward the right-hand. Few readings were obtained over $6.9 \mathrm{GPa}$ in this region, which extended lengthwise from the joint interface to the testing limits.

Along with mapping the dynamic elastic modulus results, time-frequency analysis was conducted to determine the presence of cracks in the concrete and corrosion of the reinforcement in the deck slab. This further analysis was conducted because the IE results had a high level of ambient noise in the concrete deck joints and thus were not sufficient for an accurate interpretation of the results [11]. Therefore, timefrequency analysis was adopted in this study. The advantages of time-frequency data analysis to evaluate structures have been recognized by many researchers [12-14].

Figure 6 shows the time domain signal and frequency domain signal that can be combined in a two-dimensional time-frequency plane. This two-dimensional time-frequency graph allows the target echoes in a noisy IE signal to be separated $[12,13]$. The scalograms were computed using MATLAB with the gaus 8 wavelet from the Gaussian family of wavelets.

The scalogram with the time-frequency analysis for Sta.12L presented in Figure 6(a) shows two separate frequency peak points at around $17 \mathrm{kHz}$ and $31 \mathrm{kHz}$ and a relatively slowdecaying phase of the frequency. This scalogram represents a debonding condition in the slab. Similarly, the scalogram of Sta.17-18L, shown in Figure 6(f), shows a similar pattern of slow decay of the frequency at approximately $28 \mathrm{kHz}$.
TABLE 1: Summary of results for GPR, PSPA, and coring.

\begin{tabular}{lccc}
\hline Location & GPR results [5] & PSPA results & Coring results \\
\hline Sta.1-2L & Severe & Severe & Severe \\
Sta.9-Cen & Moderate/severe & Slight & Moderate \\
Sta.9-16R & Moderate & Good & Moderate \\
Sta.17-2R & Slight & Slight & Good \\
Sta.17-12R & Good & Severe & Good \\
Sta.17-18L & Moderate & Moderate & Severe \\
\hline
\end{tabular}

For the remaining locations, Sta.9-Cen, Sta.9-16R, Sta.172R, and Sta.17-12R, shown in Figures 6(b)-6(e), respectively, the high-frequency wave components at the beginning of the signal are well separated from the continuous reflections throughout the signal. Therefore, a slab in good condition can be represented by a scalogram that shows the decaying feature of the full slab thickness frequency [8].

3.3. Verification of Test Results Using Core Samples. In order to verify the PSPA test results, $100 \mathrm{~mm}$ diameter core samples were extracted from the test area. Six locations were chosen to show sound ("good") concrete and slight, moderate, moderate/severe, and severe delamination. Because of the bridge's location over live traffic, the core drill depth was limited to $127 \mathrm{~mm}$ to prevent a sample from falling through the deck. One exception to the drill depth was at Sta.1-2L, where the core depth was limited to $76 \mathrm{~mm}$ due to the large amount of reinforcing steel encountered. A summary of the coring results is given in Table 1, and the location of each sample is shown in Figure 7. The particular details of each core specimen are described in the following sections.

For Sta.1-2L, shown in Figure 7(a), the PSPA measured a modulus value of $2.34 \mathrm{GPa}$, which indicates severe deterioration. The core sample proved that the concrete at this particular location was indeed severely deteriorated; the only retrievable section of the core from this location, a wedgeshaped disc of approximately $12 \mathrm{~mm}$ maximum thickness, 


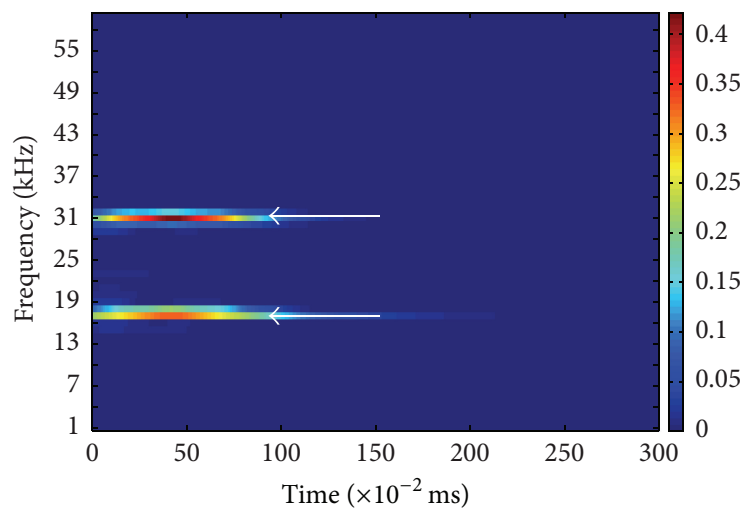

(a) Sta.1-2L

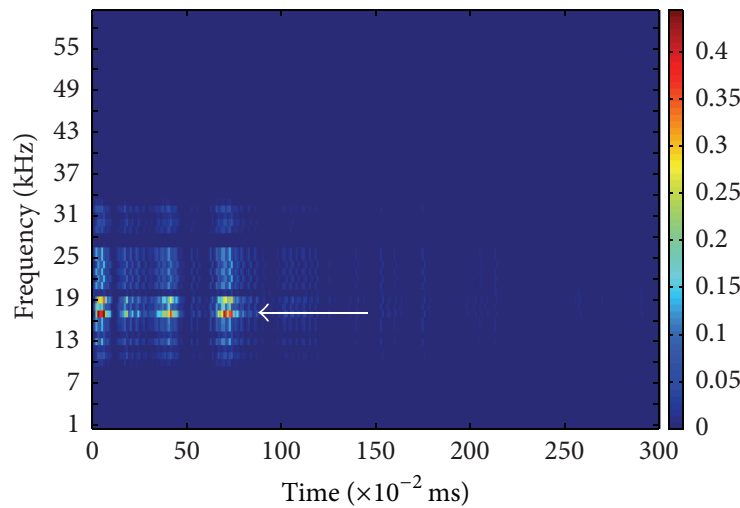

(c) Sta.9-16R

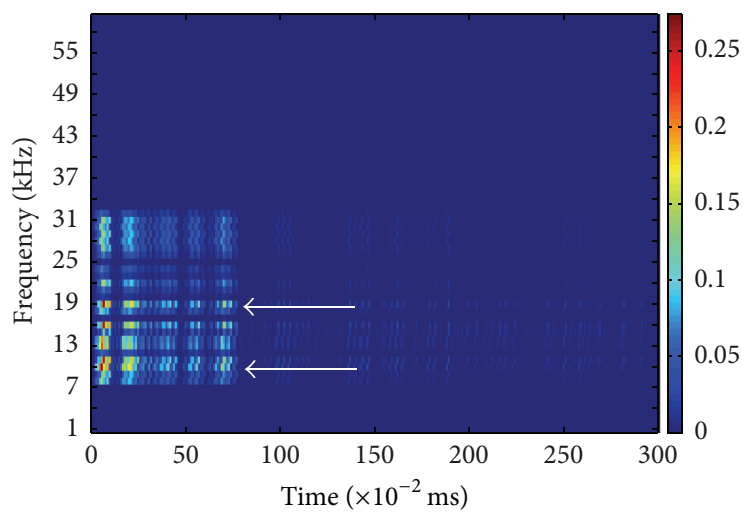

(e) Sta.17-12R

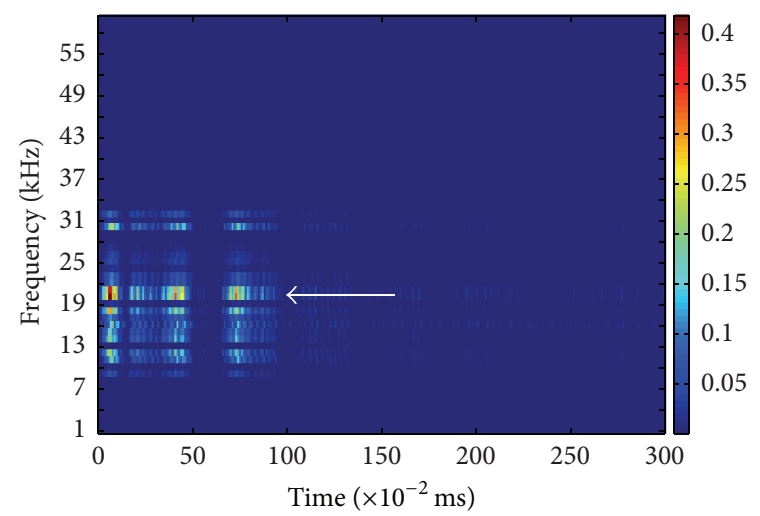

(b) Sta.9-Cen

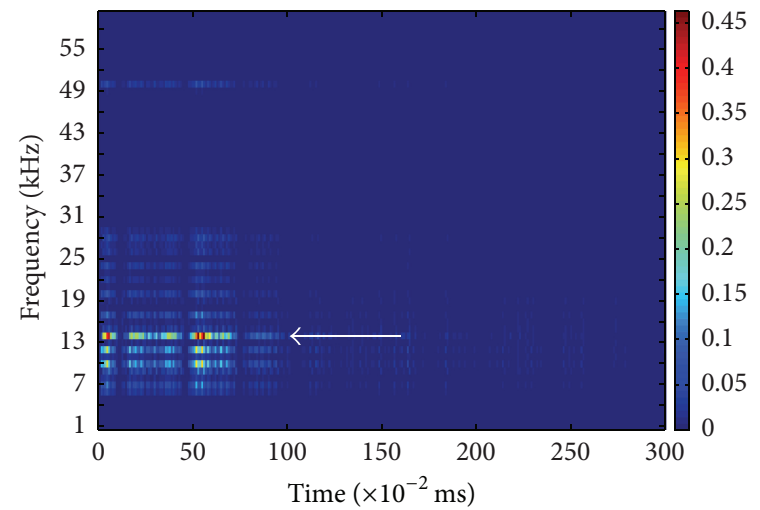

(d) Sta.17-2R

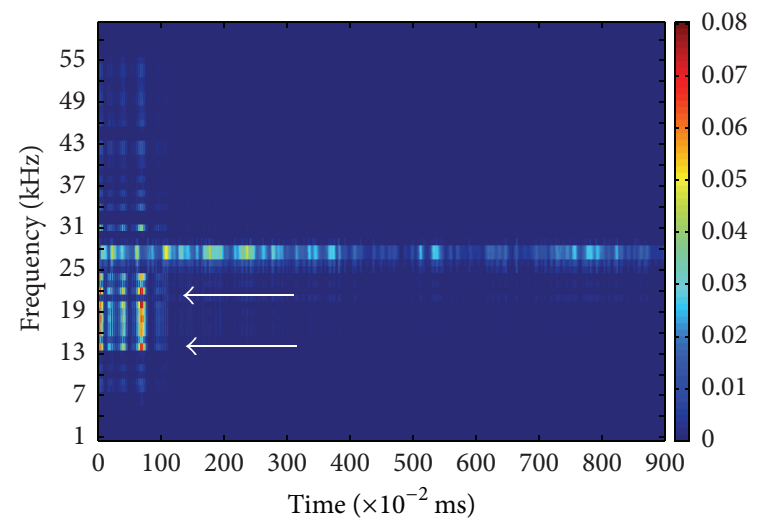

(f) Sta.17-18L

FIGURE 6: Scalograms at different test points.

was extracted from the surface. The remainder of the core consisted of coarse aggregate and small pieces of mortar that were impractical to piece together. These remnants exhibited discoloration that is indicative of extensive steel corrosion. The drill encountered severe resistance due to the large amount of reinforcing steel and was subject to binding; therefore, the coring depth was limited to $76 \mathrm{~mm}$ to avoid damage to the coring bit.

For Sta.9-Cen, shown in Figure 7(b), the PSPA measured a modulus of $29.16 \mathrm{GPa}$, indicating no deterioration. The core sample appeared to be sound overall, except that during extraction the break occurred at a depth of $83 \mathrm{~mm}$ to $108 \mathrm{~mm}$. This depth is relatively shallow compared to the actual $127 \mathrm{~mm}$ depth achieved by the coring bit. This observation, when combined with some slight fracturing of some of the coarse aggregate, is indicative of some degree of deterioration at this depth.

For Sta.9-16R, shown in Figure 7(c), the PSPA measured a modulus of $28.48 \mathrm{GPa}$, indicating no deterioration. Like the previous sample, this core appeared to be sound overall. During extraction the fracture occurred at the full $127 \mathrm{~mm}$ depth of the bit penetration. Some slight fracturing of 


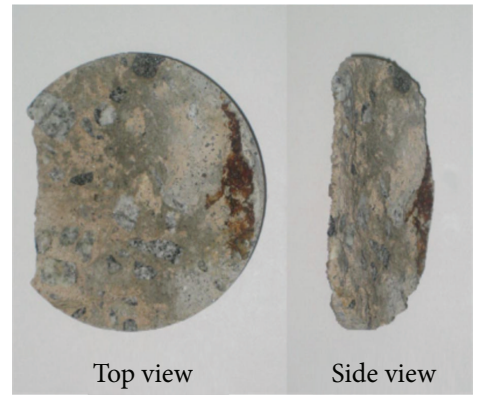

Station 1, $2 \mathrm{ft}$. left

(a) Sta.1-2L

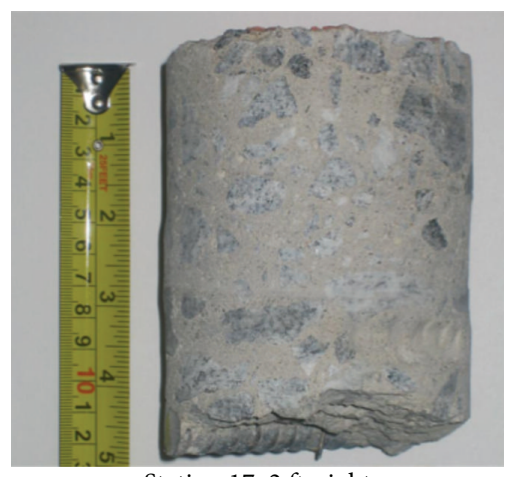

Station $17,2 \mathrm{ft}$. right

(d) Sta.17-2R

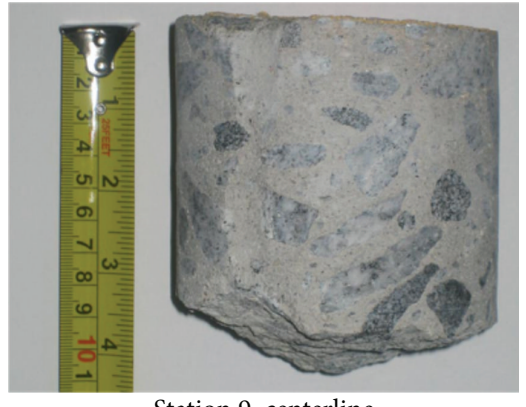

Station 9, centerline

(b) Sta.9-Cen

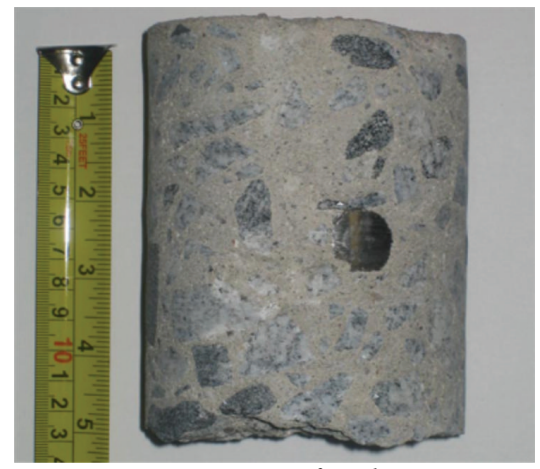

Station $17,12 \mathrm{ft}$. right

(e) Sta.17-12R

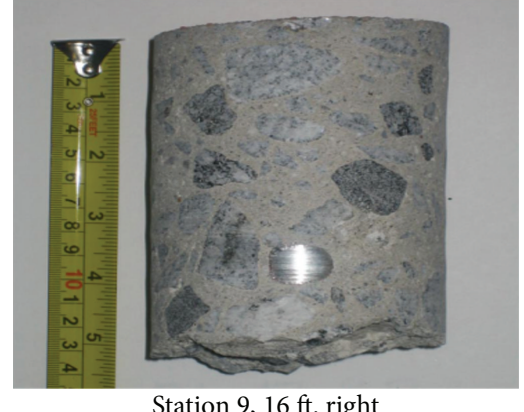

Station 9, $16 \mathrm{ft}$. right

(c) Sta.9-16R

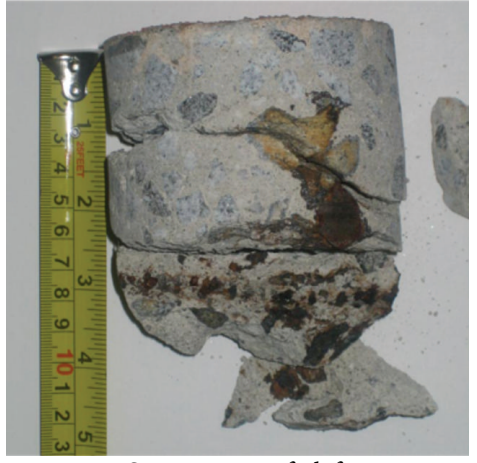

Station $17,18 \mathrm{ft}$. left

(f) Sta.17-18L

Figure 7: Core samples.

the coarse aggregate was also present at the break, again suggesting some deterioration at this depth.

For Sta.17-2R, shown in Figure 7(d), the PSPA measured a modulus of $22.06 \mathrm{GPa}$, indicating no deterioration. This specimen appeared to be in excellent shape overall, with no visible signs of delamination, discoloration, or other defects. The fracture, although located slightly deeper than the $127 \mathrm{~mm}$ coring depth, was reasonably clean and in the same plane as the reinforcing steel. No aggregate fracture was evident, further suggesting that the concrete was sound at this depth.

For Sta.17-12R, shown in Figure 7(e), the PSPA measured a modulus of $5.52 \mathrm{GPa}$, indicating severe deterioration. However, the time-frequency domain analysis provides a scalogram that is similar to that of a sound concrete core sample. This specimen appears to be very similar to the specimen extracted from Sta.9-16R. The specimen appeared to be in excellent shape overall, with no visible signs of delamination, discoloration, or other defects. The fracture was at the $127 \mathrm{~mm}$ coring depth and was reasonably clean, with no visible signs of aggregate fracture.

For Sta.17-18L, shown in Figure 7(f), the PSPA measured a modulus of $11.03 \mathrm{GPa}$, indicating moderate deterioration. A scalogram similar to that of Sta.1-2L was found from the analysis, which indicates severe deterioration. This specimen fractured into at least five separate pieces during the actual coring (not during extraction). The matching faces of each piece exhibited discoloration that indicated corrosion of the reinforcing steel. Remnants of the core below approximately $100 \mathrm{~mm}$ were similar to the remnants of the core at Sta.1-2L; these remnants consisted of coarse aggregate and small pieces of mortar.

\section{Conclusions}

The primary advantage of the PSPA as a bridge assessment tool lies in its ability to assess the concrete's modulus and to detect subsurface defects, including cracks in the concrete and corroded rebar, at a particular point simultaneously. Another benefit is that its results for a particular point are displayed in real time, without the need for further postprocessing. The good correlation between the PSPA data and the core specimen data, however, suggests that much more work needs to be done before practical engineering decisions can be made based upon its data in this application. The PSPA's ability to gather valid data appears to be impeded severely by the poor condition of the deck in this study. This issue affected the data in two ways.

The first effect involved a coupling issue. The extremely weathered condition of the deck surface made it very difficult to obtain proper coupling of the source and the receiver feet. Multiple attempts at positioning the PSPA over the test point were sometimes necessary to achieve good results. In addition to increasing the testing time, this issue also exacerbated the normal wear on the rubber coupling pads tied to the feet. 
The second effect involved the concrete's subsurface state. Major spalling of the deck surface due to corrosion of the upper layer of the reinforcing steel had already occurred in several areas. This observation was noted in the inspection report and verified in the field. Hammer blows produced a distinct hollow sound at many of the PSPA test points, which was evidence of severe delamination at the surface. The IE data further support evidence of this deterioration and suggest that the deterioration had a negative effect on the wave propagation necessary to detect specific defects at lower depths.

\section{Competing Interests}

The authors declare that there are no competing interests regarding the publication of this paper.

\section{References}

[1] American Society of Civil Engineers, Report Card for America's Infrastructure, 2009, http://www.infrastructurereportcard.org/ state-page/north-carolina.

[2] North Carolina Department of Transportation, January 2010, http://www.ncdot.org/download/projects/ncbridges/StatewideBridges.pdf.

[3] National Cooperative Highway Research Program, NCHRP Synthesis 319: Bridge Deck Joint Performance, Transportation Research Board, Washington, DC, USA, 2003.

[4] North Carolina Department of Transportation, NCDOT 2006 Standard Specifications, Project Special Provision 21, PDF Document, 2010, http://www.ncdot.org/doh/preconstruct/highway/structur/psp/newpsp06/PSP021.pdf.

[5] W. Choi, L. Rickard, T. Abu-Lebdeh, and M. Picornell, "Detection of subsurface defects in concrete bridge deck joints," American Journal of Engineering and Applied Sciences, vol. 4, no. 4, pp. 440-447, 2011.

[6] N. H. Bettigole and R. Robison, Bridge Decks: Design, Construction, Rehabilitation, Replacement, American Society of Civil Engineers, New York, NY, USA, 1997.

[7] I. Torigoe, K. Mori, and A. Spagnoli, "Signal processing procedure for non-destructive test of concrete structure integrity," NDT and E International, vol. 38, no. 7, pp. 575-581, 2005.

[8] K. Mori, A. Spagnoli, Y. Murakami, G. Kondo, and I. Torigoe, "A new non-contacting non-destructive testing method for defect detection in concrete," NDT and E International, vol. 35, no. 6, pp. 399-406, 2002.

[9] M. Sansalone, "Impact-echo: the complete story," ACI Structural Journal, vol. 94, no. 6, pp. 777-786, 1997.

[10] L. Rickard, Development of a procedure for the detection of subsurfaced defects in bridge deck joint armor using ground penetrating radar and seismic properties analysis [M.S. thesis], North Carolina A and T State University, Greensboro, NC, USA, 2011.

[11] M. Celaya, P. Shokouhi, and S. Nazarian, "Assessment of debonding in concrete slabs using seismic methods," Transportation Research Record, vol. 2016, pp. 65-75, 2007.

[12] P. Shokouhi, Comprehensive evaluation of concrete bridge decks using impact echo [Ph.D. thesis], Rutgers University, Piscataway, NJ, USA, 2006.
[13] O. Abraham, C. Léonard, P. Côte, and B. Piwakowski, "Time frequency analysis of impact-echo signals: numerical modeling and experimental validation," ACI Structural Journal, vol. 97, no. 6, pp. 645-657, 2000.

[14] D.-S. Kim, N.-R. Kim, and W.-S. Seo, "Time-frequency analysis for impact echo-SASW (IE-SASW) method," Key Engineering Materials, vol. 270-273, pp. 1529-1534, 2004. 

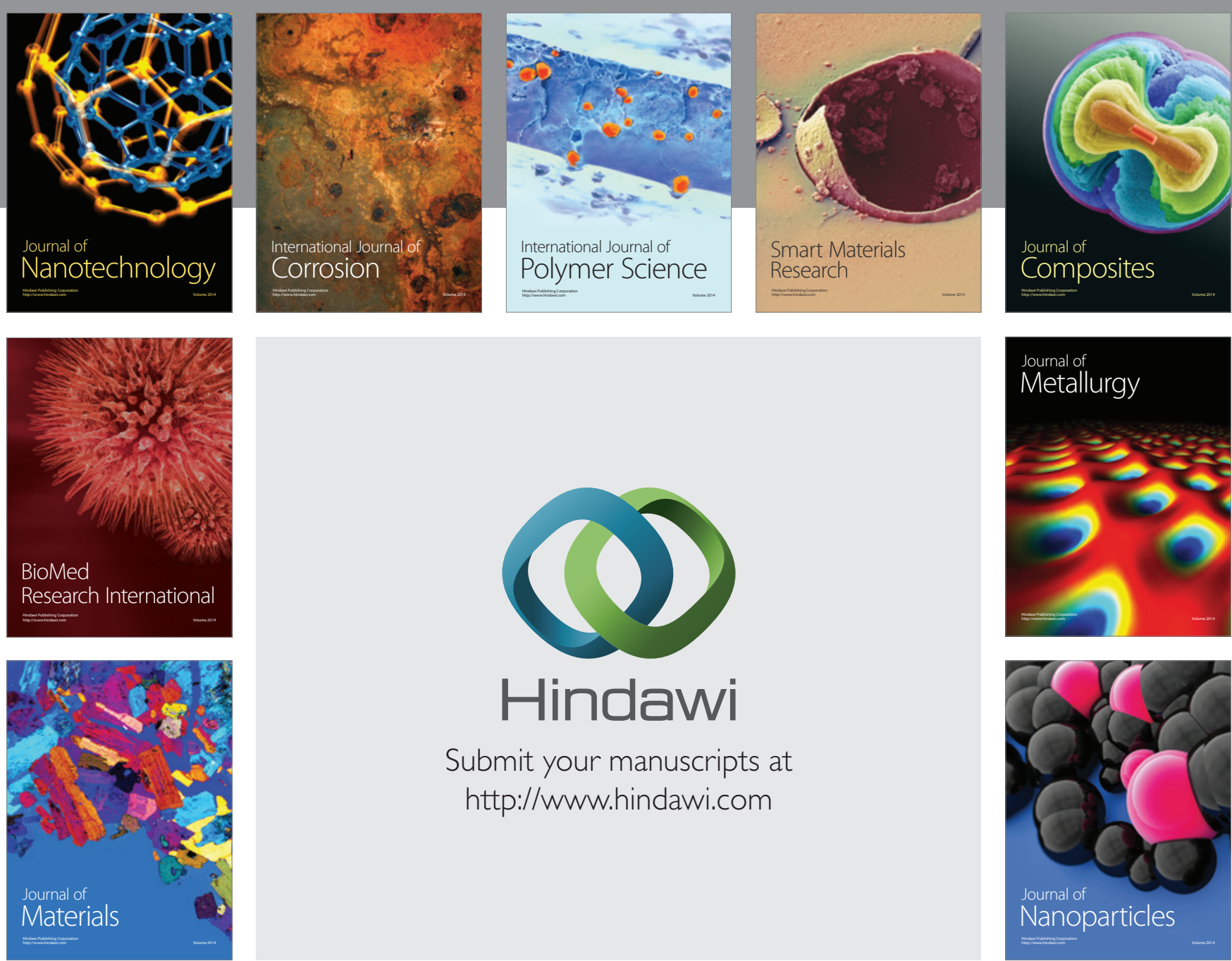

\section{Hindawi}

Submit your manuscripts at

http://www.hindawi.com

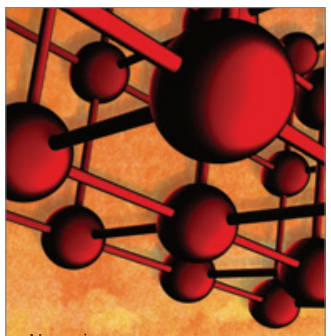

Materials Science and Engineering
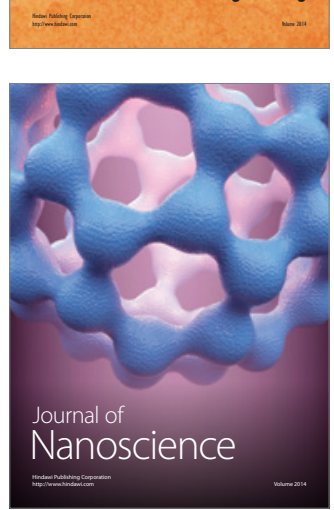
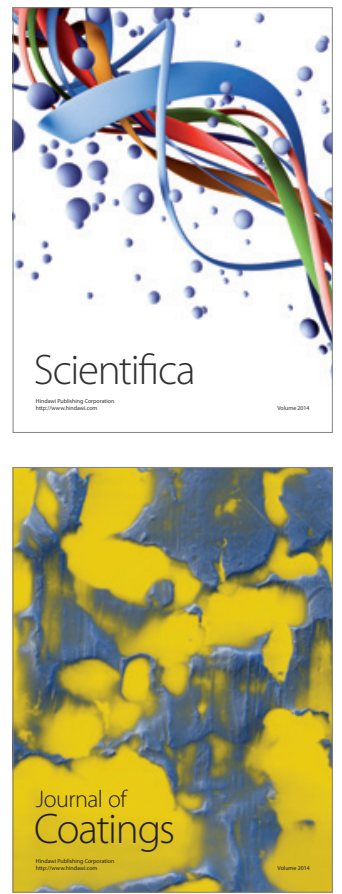
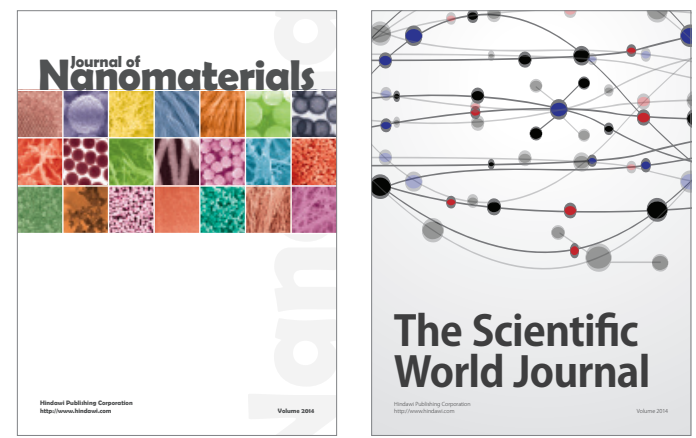

The Scientific World Journal
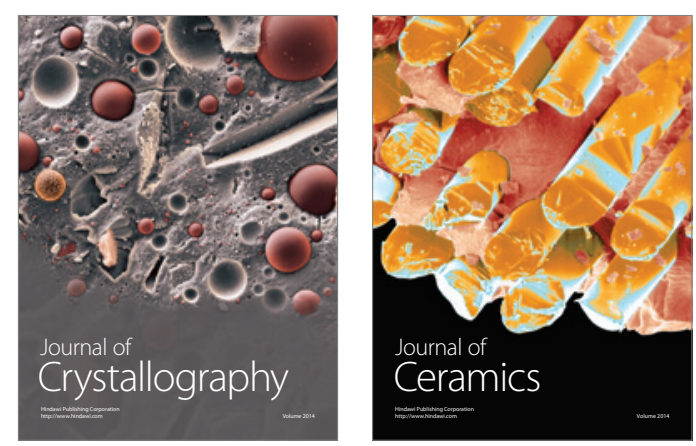
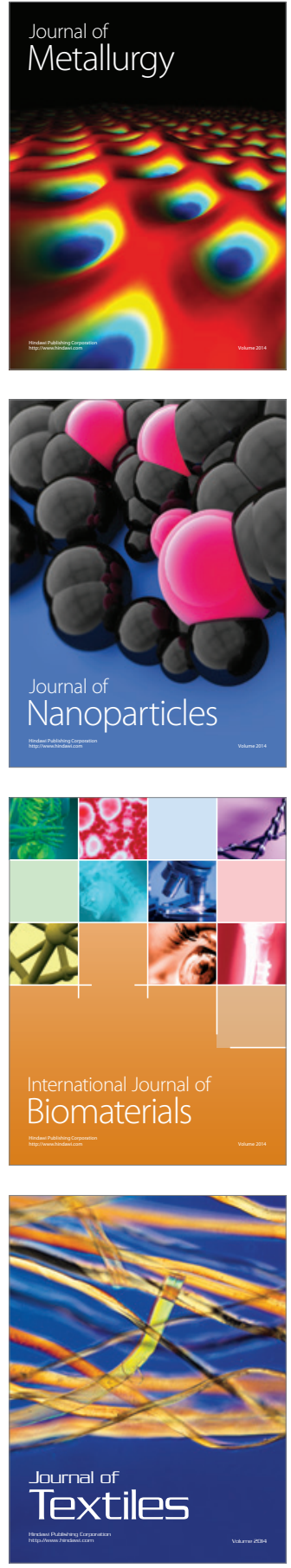